\title{
The pretreatment albumin to globulin ratio predicts survival in patients with natural killer/T-cell lymphoma
}

Xi-wen Bi, Liang Wang, Wen-wen Zhang, Shu-mei Yan, Peng Sun, Yi Xia, Zhi-ming Li, Wen-qi Jiang

Background. The pretreatment albumin to globulin ratio (AGR) has been reported to be a predictor of survival in several types of cancer. The aim of this study was to evaluate the prognostic impact of AGR in patients with natural killer/T-cell lymphoma (NKTCL).

Methods. We retrospectively reviewed the available serum biochemistry results for 331 NKTCL patients before treatment. AGR was calculated as albumin/ (total protein - albumin), and a cut-off value of 1.3 was used to define AGR as low or high. Survival analysis was used to assess the prognostic value of AGR.

Results. A low AGR (<1.3) was associated with significantly more adverse clinical features, including old age, poor performance status, advanced stage, elevated lactate dehydrogenase, B symptoms, and high International Prognostic Index (IPI) and natural killer/T-cell lymphoma prognostic index (NKPI) scores. Patients with a low AGR had a significantly lower 5 -year overall survival (44.5 vs. $65.2 \%, P<0.001$ ) and progression-free survival ( 33.1 vs. $57.4 \%, P<0.001$ ). In the multivariate analysis, a low AGR remained an independent predictor of poorer survival. Additionally, AGR distinguished patients with different outcomes in the IPI low-risk group and in the NKPI high-risk group.

Discussion. Pretreatment AGR may serve as a simple and effective predictor of prognosis in patients with NKTCL. 
1 The pretreatment albumin to globulin ratio predicts survival in patients with natural

2 killer/T-cell lymphoma

3 Authors and affiliations:

4 Xi-wen $\mathrm{Bi}^{1,5,6}$, Liang Wang ${ }^{2,5,6}$, Wen-wen Zhang ${ }^{3,5,6}$, Shu-mei Yan ${ }^{4,5,6}$, Peng Sun ${ }^{1,5,6}$, Yi Xia ${ }^{1,}$

5 5, 6, Zhi-ming Li ${ }^{1,5,6}$, Wen-qi Jiang ${ }^{1,5,6}$

6 Xi-wen Bi, Liang Wang, and Wen-wen Zhang contributed equally to this work.

$7{ }^{1}$ Department of Medical Oncology, Sun Yat-sen University Cancer Center, Guangzhou,

8 Guangdong, People's Republic of China

$9{ }^{2}$ Department of Hematologic Oncology, Sun Yat-sen University Cancer Center, Guangzhou,

10 Guangdong, People's Republic of China

$11{ }^{3}$ Department of Radiation Oncology, Sun Yat-sen University Cancer Center, Guangzhou,

12 Guangdong, People's Republic of China

$13{ }^{4}$ Department of Pathology, Sun Yat-sen University Cancer Center, Guangzhou, Guangdong,

14 People's Republic of China

$15{ }^{5}$ State Key Laboratory of Oncology in South China, Guangzhou, Guangdong, People's Republic

16 of China

$17{ }^{6}$ Collaborative Innovation Center for Cancer Medicine, Guangzhou, Guangdong, People's

18 Republic of China

19 Corresponding author: Wen-qi Jiang. Department of Medical Oncology, Sun Yat-sen

20 University Cancer Center, 651 Dong Feng East Road, Guangzhou, Guangdong, 510060,

21 People's Republic of China. Tel: +86-20-87343765. E-mail: wenqi_jiang@163.com 


\section{Abstract}

24 Background. The pretreatment albumin to globulin ratio (AGR) has been reported to be a predictor of survival in several types of cancer. The aim of this study was to evaluate the prognostic impact of AGR in patients with natural killer/T-cell lymphoma (NKTCL).

Methods. We retrospectively reviewed the available serum biochemistry results for 331 NKTCL patients before treatment. AGR was calculated as albumin/ (total protein - albumin), and a cutoff value of 1.3 was used to define AGR as low or high. Survival analysis was used to assess the prognostic value of AGR.

Results. A low AGR $(<1.3)$ was associated with significantly more adverse clinical features, including old age, poor performance status, advanced stage, elevated lactate dehydrogenase, B symptoms, and high International Prognostic Index (IPI) and natural killer/T-cell lymphoma prognostic index (NKPI) scores. Patients with a low AGR had a significantly lower 5-year overall survival (44.5 vs. $65.2 \%, P<0.001)$ and progression-free survival $(33.1$ vs. $57.4 \%, P<$ 0.001). In the multivariate analysis, a low AGR remained an independent predictor of poorer survival. Additionally, AGR distinguished patients with different outcomes in the IPI low-risk group and in the NKPI high-risk group.

Discussion. Pretreatment AGR may serve as a simple and effective predictor of prognosis in 40 patients with NKTCL. 


\section{Introduction}

Extranodal natural killer/T-cell lymphoma (NKTCL) is a relatively rare lymphoid malignancy (Chim et al., 2004; Vose et al., 2008). Most cases of NKTCL initially arise in the nasal cavity and are diagnosed at an early stage. However, destructive and ulcerative lesions and the frequent involvement of neighboring tissues indicate an invasive biological behavior (Chan, Jaffe \& Ralfkiaer, 2001; Chan et al., 2008). NKTCL is highly radiosensitive, and radiotherapy (RT) has been well established as the primary treatment for localized disease (Li et al., 2006; Li et al., 2012; Bi et al., 2013). Probably due to the expression of a multidrug-resistant gene in tumor cells, NKTCL is relatively refractory to anthracycline-based chemotherapy regimens (Wang et al., 2008; Kim et al., 2009). However, novel regimens containing L-asparaginase (LASP) or pegaspargase have shown encouraging results (Jaccard et al., 2011; Yamaguchi et al., 2011; Kwong et al., 2012). A heterogeneous treatment response and prognosis have been observed in patients with NKTCL, making accurate prognostic stratification at diagnosis important. Previous studies have identified various prognostic factors in NKTCL, such as the stage of disease, local tumor invasion, B symptoms, and the plasma Epstein-Barr virus (EBV) DNA copy number (Lee et al., 2006; Au et al., 2009; Wang et al., 2012; Bi et al., 2015b). The International Prognostic Index (IPI) and natural killer/T-cell lymphoma prognostic index (NKPI) have been the most commonly used models for prognostic stratification in NKTCL (Shipp et al., 1993; Chim et al., 2004; Lee et al., 2006). However, the value of currently reported prognostic indicators of NKTCL remains controversial because: (1) the prognostic power of some factors could not be consistently verified among different cohorts, such as local tumor invasion and IPI score (Cheung et al., 2002; Lee et al., 2006); and (2) distribution of patients into different risk groups based on the currently used IPI or NKPI models was disproportional with a majority of patients in the low-risk group, as previously reported (Chim et al., 2004; Huang et al., 2011).

It is well accepted that inflammatory reactions play an important role in promoting tumor progression and invasion, reducing the treatment response and worsening the prognosis (Colotta et al., 2009). Hypoalbuminemia is usually related to malnutrition. However, previous studies have found that hypoalbuminemia may be used as an effective indicator of up-regulated cancerrelated inflammatory response, which is mainly attributed to the cytokine-induced suppression of albumin synthesis and increased albumin degradation (Andersson et al., 1990; Fearon et al., 1998). Serum globulins play a key role in immunity and inflammation, and elevated levels of serum globulin are usually associated with enhanced inflammatory response (Gabay \& Kushner 1999). Both decreased albumin levels and increased globulin levels have been associated with up-regulated inflammation and poor outcome for several types of cancer (Boonpipattanapong \& Chewatanakornkul 2006; Siddiqui et al., 2007; Gabay \& Kushner 1999; Gupta \& Lis 2010; 
76 Guthrie et al., 2013; McMillan et al., 2001). Therefore, a low albumin to globulin ratio (AGR)

77 may amplify the predictive power of these two elements and serve as a more robust predictor of

78 an enhanced inflammatory and adverse survival in cancer patients (Azab et al., 2013a; Azab et al., 2013b). In recent studies, low AGR has been reported to be an adverse prognostic factor in patients with colorectal cancer (Azab et al., 2013b; Shibutani et al., 2015), breast cancer (Azab et al., 2013a), and lung cancer (Duran et al., 2014). A strong association between NKTCL and inflammatory reactions has been proposed. Pathologically, the lesions are characterized by coagulative necrosis and a diffuse inflammatory infiltrate. Clinically, ulcerative and destructive lesions, purulent rhinorrhea, and fever are very common manifestations (Chan, Jaffe \& Ralfkiaer, 2001; Chan et al., 2008). However, previously identified prognostic factors of NKTCL were mainly related to tumor burden and patient status, and rarely focused on lymphoma-related inflammatory markers. Therefore, as an effective indicator of cancer related inflammatory reactions, the prognostic value of AGR may be worth further study in NKTCL. In this study, we retrospectively collected data related to AGR in a large cohort of patients with NKTCL and analyzed correlations with clinical features and prognosis.

\section{Materials and Methods}

\section{Patient selection and baseline evaluation}

The medical records of 385 previously untreated patients with NKTCL who were treated at Sun Yat-sen University Cancer Center between 2001 and 2013 were reviewed. The inclusion criteria included: (1) diagnosis of NKTCL according to the World Health Organization (WHO) classification of lymphomas (Chan, Jaffe \& Ralfkiaer, 2001; Chan et al., 2008); (2) complete laboratory data before initial treatment; and (3) complete follow-up data. The exclusion criteria were: (1) known active inflammatory disorders including autoimmune disease and infection; (2) known active liver or kidney disease; and (3) receiving supportive care alone, without chemotherapy or radiotherapy (RT). A total of 331 patients were included in this study. Written informed consent for the collection of medical information was obtained from all patients at the first visit. The ethics committee of Sun Yat-sen University Cancer Center approved this study (No. B2015-054-01).

Baseline evaluations included a medical history and physical examination; complete blood count; serum biochemistry (including lactate dehydrogenase (LDH) level); computed tomography and/or magnetic resonance imaging of the head and neck; computed tomography of the chest, abdomen, and pelvis; and a bone marrow examination. Patients were staged according to the Ann Arbor system. The International Prognostic Index (IPI, including age, performance 
110

111

112

113

114

115

116

117

118

119

120

121

122

123

124

125

126

127

128

129

130

131

132

133

134

135

136

137

138

139

140

141

142

status, stage of disease, LDH level, and number of extranodal lesions) and the natural killer/Tcell lymphoma prognostic index (NKPI, including stage of disease, the involvement of regional lymph nodes, B symptoms, and LDH level) were calculated for all patients (Shipp et al., 1993; Lee et al., 2006). The primary sites of disease were classified into the upper aerodigestive tract (UAT, including the nasal cavity, Waldeyer's ring, hypopharynx, larynx, and oral cavity) and the extra-UAT (any site other than a UAT site) (Kim et al., 2008). Total serum protein and serum albumin were measured using an automated immunoturbidimetric analyzer (7600-020; Hitachi High-Technologies, Tokyo, Japan) within seven days before initial treatment. The AGR was calculated as albumin/ (total protein - albumin).

\section{Treatment}

The treatment modality has been described previously (Bi et al., 2015a). Patients with early stage disease received induction chemotherapy followed by involved-field radiotherapy (IFRT). Patients with advanced disease received chemotherapy as the primary treatment, and IFRT could be delivered as consolidation, palliative or salvage therapy according to the physician's clinical judgment. As previously reported (Bi et al., 2015a; Bi et al., 2015b), chemotherapy regimens varied over the study period but were categorized as an asparaginase (ASP)-containing or anthracycline-based regimen, depending on whether L-ASP or pegaspargase was incorporated. IFRT was administered in daily fractions of 2.0-2.5 Gy (5 days a week), with a median dose of 54.6 Gy (range, 18.0-74.0 Gy).

\section{Follow-up and statistical analysis}

The follow-up schedule has been reported previously (Wang et al., 2014). The overall survival (OS) was measured from the date of diagnosis to the date of death due to any cause or the date of the most recent follow-up. Progression-free survival (PFS) was measured from the date of diagnosis to the date of disease progression, relapse, death due to any cause, or the most recent follow-up. The survival data were calculated using the Kaplan-Meier method and compared using the log-rank test. Continuous variables were presented as medians (range) and were compared using the Mann-Whitney U-test. Categorical variables were reported as frequencies and percentages and were compared using the Chi-squared test. The Cox proportional hazard model was used for a univariate screen of all potential predictors of survival. Variables with statistical and clinical significance were included in the multivariate analysis using the stepwise forward Cox regression model. Results were considered statistically 
143

144

145

146

147

148

149

150

151

152

153

154

155

156

157

158

159

160

161

162

163

164

165

166

167

168

169

170

171

172

173

174

significant with a two-sided $P$ value $<0.05$. The statistical analysis was performed using SPSS version 17.0 software (SPSS A, Inc., Chicago, IL, USA).

\section{Results}

\section{Determination of the optimal cut-off value for AGR}

The optimal cut-off point to define a high or low AGR was determined using the method proposed by Igarashi et al. (Igarashi et al., 2001). Using the log-rank test, we examined the discriminative power of different cut-off values for the prediction of OS from 1.0 to 2.0 in steps of 0.1 . The cut-off value at which the OS curves separated most significantly (i.e., 1.3) was selected to categorize the AGR as low or high (Table 1). A total of $117(35.3 \%)$ patients had a low AGR and 214 (64.7\%) had a high AGR.

\section{Clinical features and treatment}

In Table 2, the clinical characteristics and treatment modalities of the cohort are presented and compared between patients with a low or high AGR. The cohort primarily comprised males (male/female ratio, 2.2:1). The median age of the patients was 42 years, with $15.4 \%$ of patients aged older than 60 years. Most of the patients presented with a good performance status (84.3\%), primary disease originating from UAT (88.8\%), and early-stage disease (81.3\%). A total of 52.3 and $29.0 \%$ of the patients had B symptoms and elevated LDH levels, respectively. The IPI was scored as $0-1$ in $78.2 \%$ of patients, and the NKPI score was $0-2$ in $81.0 \%$ of patients.

The baseline characteristics differed significantly between patients with a low or high AGR. As shown in Table 2, patients in the low AGR group presented with significantly more adverse clinical features, including advanced disease (stage III-IV: 25.6 vs. $15.0 \%, P=0.017$ ), elevated LDH (40.2 vs. $22.9 \%, P=0.001$ ), B symptoms ( 73.5 vs. $40.7 \%, P<0.001$ ), involvement of regional lymph nodes (49.6 vs. $28.5 \%, P<0.001)$, and a higher IPI score $(P<0.001)$ and NKPI score $(P<0.001)$. Patients with a low AGR were slightly older $(>60$ years: 20.5 vs. $12.6 \%, P=$ 0.057), had a significantly worse Eastern Cooperative Oncology Group (ECOG) performance score ( $\geq 2: 28.2$ vs. $8.9 \%, P<0.001$ ), and had a lower median body mass index (BMI, 20.4 vs. $21.4, P=0.010$ ). Serum albumin (median: 38.0 vs. $43.5, P<0.001$ ) and absolute lymphocyte count (median: 1.4 vs. 1.6, $P=0.032$ ) were significantly lower in the low AGR group compared with the high AGR group, while C-reactive protein (CRP; median: 12.8 vs. $3.9, P<0.001)$ and the erythrocyte sedimentation rate (ESR, 41 vs. $11, P<0.001$ ) were markedly higher in the low 
175

176

177

178

179

180

181

182

183

184

185

186

187

188

189

190

191

192

193

194

195

196

197

198

199

200

201

202

203

204

205

206

207

208

AGR group. In addition, primary lesions in the upper aerodigestive tract were less frequently observed in the low AGR group ( 83.8 vs. $91.6 \%, P=0.031$ ). Serum creatinine was higher in the high AGR group than compared with the low AGR group (median: 69.3 vs. 64.1, $P=0.011$ ).

As shown in Table 2, 67.7\% of patients underwent RT with or without chemotherapy as the first-line treatment, while $32.3 \%$ received chemotherapy alone. Anthracycline-based and ASPcontaining chemotherapeutic regimens were administered to 60.7 and $39.3 \%$ of patients, respectively. The median dose of radiation was $54.6 \mathrm{~Gy}$ (range, 18.0-74.0 Gy), and the median number of chemotherapy cycles was 4 (range, $0-10$ ). The treatment modalities differed significantly between patients in the low and high AGR groups (Table 2). There were significantly more patients receiving chemotherapy alone without RT in the low AGR group than in the high AGR group (43.6 vs. $26.2 \%, P=0.001$ ). ASP-containing chemotherapeutic regimens were used more frequently in the low AGR group than in the high AGR group (49.1 vs. 34.0\%, $P$ $=0.008)$. However, the dose of radiation and number of chemotherapy cycles were comparable between the two groups.

\section{Prognosis and univariate screen of prognostic factors}

At a median follow-up of 37.1 months (range, 4.5-153.8 months) for surviving patients, the 5-year OS and PFS for the entire cohort were 58.1 and 49.6\%, respectively (Fig. 1). A total of $127(38.4 \%)$ patients died from lymphoma $(n=119)$, treatment-related complications $(n=3)$, comorbidities $(n=4)$, or unknown causes $(n=1)$. Patients with an AGR $<1.3$ had a significantly poorer prognosis compared with patients with an AGR $\geq 1.3$. The 5-year OS rates were 44.5 and $65.2 \%$ in the low and high AGR groups, respectively $(P<0.001$, Fig. $2 \mathrm{~A})$. The 5 -year PFS rates were 33.1 and $57.4 \%$ in the low and high AGR groups, respectively $(P<0.001$, Fig. 2B).

Table 3 shows the results from the univariate screening of prognostic factors for OS and PFS. The hazard ratio (HR) of each unit increase in AGR was 0.32 [95\% confidence interval (CI) 0.17-0.61, $P<0.001]$ for OS. The HR for the OS of the patients in the low AGR group was 2.09 (95\% CI: 1.47-2.97, $P<0.001)$ compared with the high AGR group. Higher mortality risks were observed in patients aged $>60$ years, those with an ECOG score $\geq 2$, a primary lesion in the EUAT, Ann Arbor stage III-IV, B symptoms, elevated LDH, involvement of regional lymph nodes, and those with two or more extranodal lesions. Each unit increase in CRP, IPI, or NKPI was associated with an increase in mortality, while each unit increase in serum total protein, albumin, white blood cell (WBC) count, or lymphocyte count was associated with a significant decrease in mortality. In terms of treatment modality, a significantly worse prognosis was observed in patients who received chemotherapy alone (compared with RT with or without 
209

210

211

212

213

214

215

216

217

218

219

220

221

222

223

224

225

226

\section{7}

228

229

230

231

232

233

234

235

236

237

238

239

240

241

chemotherapy) or anthracycline-based chemotherapy (compared with ASP-containing regimens). The BMI, neutrophil count, ESR, and serum creatinine had no significant impact on mortality risk.

\section{Multivariate analysis of prognostic factors}

The variables that had a significant impact on survival in the univariate analysis were included in the multivariate Cox regression model (Table 4). Serum total protein and albumin were excluded because they were used to calculate AGR. The IPI and NKPI were excluded because they were calculated using several individual factors (i.e., age, ECOG score, stage, B symptoms, LDH, regional lymph node involvement, and extranodal sites $\geq 2$ ) that were already included in the model. CRP was excluded as it is a constituent of serum globulin and affects the calculation of AGR. We ran two separate Cox regression models using AGR as a binary variable $(<1.3$ vs. $\geq 1.3)$ and as a continuous variable (per unit increase). After adjusting for confounding variables, an AGR $<1.3$ remained an independent adverse predictor for both OS (HR: 1.74, 95\% CI: $1.18-2.56, P=0.005$ ) and PFS (HR: $1.73,95 \%$ CI: $1.21-2.48, P=0.003$ ). Similarly, each unit increase in AGR was an independent predictor for improved OS (HR: 0.33, 95\% CI: 0.17$0.66, P=0.002)$ and PFS (HR: $0.40,95 \%$ CI: $0.22-0.75, P=0.004)$ in the other model.

\section{Additional analyses}

Further subgroup analyses were performed to determine if the prognostic significance of AGR was merely a function of hypoalbuminemia or early death. Among the 293 patients with normal serum albumin levels (defined as albumin $\geq 35 \mathrm{~g} / \mathrm{L}$ ), an AGR $<1.3$ was associated with significantly worse 5 -year OS (53.3 vs. $67.7 \%, P=0.005)$ and PFS (44.3 vs. $59.6 \%, P=0.005$ ). Among the 281 patients who survived for more than 6 months after diagnosis, those with an AGR $<1.3$ had a significantly worse 5 -year OS (58.6 vs. $72.3 \%, P=0.017)$ and PFS (44.0 vs. $63.7 \%, P=0.004)$.

Subgroup analyses were also performed based on treatment modalities. An AGR $<1.3$ significantly worsened the 5 -year OS (19.9 vs. $36.6 \%, P=0.013$, Fig. $3 \mathrm{~A})$ and PFS (11.6 vs. $31.8 \%, P=0.009)$ in the 107 patients who received chemotherapy alone. Among the 224 patients who received RT, those with an AGR $<1.3$ had a slightly worse 5-year OS (63.9 vs. $74.6 \%, P=$ 0.070 , Fig. 3B) and significantly inferior 5-year PFS (52.6 vs. $66.4 \%, P=0.037)$ compared with those with a higher AGR. In the 193 patients who received anthracycline-based chemotherapy, an AGR $<1.3$ was associated with significantly worse 5 -year OS (33.0 vs. 58.8\%, $P<0.001$, Fig. 
242 3C) and PFS (21.9 vs. 48.9\%, $P<0.001)$. Similarly, an AGR $<1.3$ was also associated with 243 significantly inferior 5-year OS (63.5 vs. 82.0\%, $P=0.013$, Fig. 3D) and PFS (51.5 vs. 79.3\%, $P$ $244=0.008)$ in patients who received ASP-containing chemotherapy.

245 As shown in Table 2, the IPI stratified patients into low-risk (scored 0-1, 259 cases, 78.2\%), 246 intermediate-risk (scored 2-3, 50 cases, 15.1\%), and high-risk groups (scored 4-5, 22 cases, $2476.6 \%$ ). These three groups differed substantially in their prognoses (3-year OS: 70.5, 31.0, and $2484.5 \%$ for the low-, intermediate-, and high-risk groups, respectively, $P<0.001$, Fig. 4A).

249 However, the IPI low-risk group could be further divided into two separate subgroups with 250 significantly different survival (3-year OS: 75.3 vs. $58.4 \%, P=0.016$ ) using an AGR $<1.3$ or $\geq$ 251 1.3. Accordingly, the entire cohort could be classified into four groups with different survivals 252 using the IPI in combination with AGR (Fig. 4B). AGR failed to distinguish prognostic subsets 253 among patients in the IPI intermediate- or high-risk groups (data not shown).

254

255

256

257

Similarly, the NKPI stratified patients into low-risk (scored 0, 101 cases, 30.5\%), intermediate-risk (scored 1-2, 167 cases, 50.5\%), and high-risk groups (scored 3-4, 63 cases, $19.0 \%$ ) with significantly different prognoses (3-year OS: 77.9, 61.6, and 28.1\% for the low-, intermediate-, and high-risk groups, respectively; $P<0.001$, Fig. 4C). AGR differentiated patients with different prognoses in the NKPI high-risk group (3-year OS: 38.9 vs. $20.1 \%, P=$ 0.047 ) and divided the entire cohort into four risk groups in combination with the NKPI (Fig. 4D). AGR failed to distinguish prognostic subsets among patients in the NKPI low- or intermediate-risk groups (data not shown).

\section{Discussion}

To our knowledge, this is the first study reporting the clinical and prognostic implications of pretreatment AGR in patients with NKTCL. Our findings demonstrated notable differences in clinical behavior between the low and high AGR groups. Patients with a pretreatment AGR $<1.3$ presented with significantly more adverse clinical features compared with those with an AGR $\geq$ 1.3, and a low AGR was independently associated with a poorer prognosis. In addition, AGR could further distinguish patients with different prognoses in the IPI low-risk group and NKPI high-risk group, and AGR in combination with these indices achieved an improved prognostic stratification for the entire cohort.

In previous studies, AGR has been reported as a predictor of mortality in several types of cancer, including breast cancer (Azab et al., 2013a), colorectal cancer (Azab et al., 2013b; Shibutani et al., 2015), lung cancer (Duran et al., 2014), and nasopharyngeal carcinoma (Du et al., 
275

276

277

278

279

280

281

282

283

284

285

286

287

288

289

290

291

292

293

294

295

296

297

298

299

300

301

302

303

304

305

306

307

308

309

2014). A recent large-scale study also revealed that low AGR was a risk factor for cancer incidence and mortality in a healthy population (Suh et al., 2014). One possible underlying mechanism is an inflammatory reaction, which has been reported to be involved in the tumor's growth, invasion, metastasis, and resistance to treatment (Balkwill \& Mantovani 2001; Coussens $\&$ Werb 2002; Colotta et al., 2009). Albumin and globulins are the two primary constituents of serum total protein. Hypoalbuminemia is generally regarded as an indicator of malnutrition. However, many studies have demonstrated that the cancer-related systemic inflammatory response has a more significant impact on hypoalbuminemia (McMillan et al., 2001), which is mainly attributed to the cytokine-induced suppression of albumin synthesis and its increased degradation (Andersson et al., 1990; Fearon et al., 1998). Serum globulins, including immunoglobulins, CRP, complement, and other acute-phase proteins, play a pivotal role in immunity and inflammation (Gabay \& Kushner 1999). Both decreased albumin and increased globulin have been reported to be associated with severity and poor outcome for several types of cancer (Boonpipattanapong \& Chewatanakornkul 2006; Siddiqui et al., 2007; Gupta \& Lis 2010; Guthrie et al., 2013). Therefore, a low AGR as a combination of these two parameters is considered a more robust predictor of an enhanced inflammatory process and a poorer prognosis.

NKTCL is a relatively rare type of lymphoid malignancy. This disease demonstrates prominent inflammatory characteristics in terms of its pathological, laboratory, and clinical features. Tumor tissues frequently exhibit an angioinvasive pattern with extensive coagulative necrosis and a diffuse polymorphous infiltrate. The typical manifestation involves a destructive nasal lesion with ulceration and purulent discharge. B symptoms (fever, night sweats, and weight loss) are usually observed (52\% in our cohort) (Chan, Jaffe \& Ralfkiaer, 2001; Chan et al., 2008). In addition, high levels of inflammatory markers, such as CRP and soluble interleukin-2 receptor (sIL-2R), were found to be predictive of poor survival in NKTCL patients in previous studies ( $\mathrm{Li}$ et al., 2013; Hanakawa et al., 2014). In the present study, NKTCL patients with low AGR experienced significant adverse clinical events, including advanced cancer stage, elevated LDH, B symptoms, multiple extranodal involvement, higher IPI and NKPI scores, and an inferior performance status. However, after controlling for these confounding variables, low AGR remained an independent predictor of poorer survival. Further, low AGR maintained its prognostic power in the patients who survived beyond 6 months after their initial diagnosis, suggesting that its predictive value was not merely due to the relatively high short-term mortality observed with this aggressive type of lymphoma.

The exact mechanism underlying the predictive power of AGR in NKTCL remains to be further investigated. Low AGR was associated with lower BMI and serum albumin in our cohort (Table 2). However, BMI had no significant survival impact, and AGR still maintained its 
310

311

312

313

314

315

316

317

318

319

320

321

322

323

324

325

326

327

328

329

330

331

332

333

334

335

336

337

338

339

340

341

342

343

344

predictive value in patients with normal albumin levels ( $88.5 \%$ of the cohort). Conversely, a low AGR correlated with stronger inflammatory clinical and laboratory profiles, including more frequently observed B symptoms and higher ESR and serum CRP levels. Both B symptoms and a high CRP significantly worsened the prognosis in our cohort. Thus, we speculate that chronic inflammation (rather than malnutrition) plays a major role in the prognostic power of AGR. In addition, patients with active inflammatory disorders and liver or kidney disease were excluded before the analysis, negating the possibility that the association between a low AGR and survival was due to the aforementioned conditions.

The IPI has been the most commonly used tool for risk stratification in non-Hodgkin's lymphoma (Shipp et al., 1993), but its role in NKTCL remains controversial (Chim et al., 2004). The newly proposed NKPI appears to have better prognostic potential than the IPI (Lee et al., 2006). However, the factors included in the two models are primarily related to tumor burden (stage, LDH, number of extranodal diseases, and lymph node involvement) and patient characteristics (age and performance status). The only inflammation-related parameter is B symptoms (in the NKPI model). Consistent with previous reports (Lee et al., 2006; Au et al., 2009), our results revealed that the IPI placed $78.2 \%$ of patients in the low-risk group. Moreover, the absolute 3-year survival differences between the IPI low- and intermediate-risk groups (39.5\%, Fig. 4A) and between the NKPI intermediate- and high-risk groups (33.5\%, Fig. 4C) were relatively large, suggesting imbalanced distributions in these risk groups. After adding AGR into the two models, patients with different outcomes were further discriminated in the IPI low-risk and in the NKPI high-risk groups. Additionally, AGR in combination with the IPI or NKPI divided the entire cohort into four risk groups with significant but more balanced survival differences (Fig. 4B and 4D). Our results suggest that introducing an inflammation-related parameter such as AGR may improve the discriminative power of the current IPI and NKPI, a notion that requires further validation in other cohorts.

Due to the rarity of this disease, no standard treatment regimen has been established for NKTCL. However, it is well accepted that RT is the most important treatment for early-stage NKTCL (Li et al., 2006; Huang et al., 2008; Li et al., 2012; Bi et al., 2013). Anthracycline-based chemotherapeutic regimens have demonstrated disappointing efficacy (Wang et al., 2008; Kim et al., 2009), but regimens containing L-ASP or pegaspargase have shown promising responses based on the results from retrospective studies (Jaccard et al., 2011; Yamaguchi et al., 2011; Kwong et al., 2012). In our cohort, the low AGR group received significantly less RT and more ASP-containing chemotherapy (Table 2), both of which were independent predictors of outcome (Table 4). However, low AGR maintained its adverse impact on survival in patients who underwent RT or no RT, as well as in patients who received anthracycline-based or ASP- 
345

346

347

348

349

350

351

352

353

354

355

356

357

358

359

360

361

362

363

364

365

366

367

368

369

370

371

372

373

374

375

containing chemotherapy (Fig. 3). These results suggest that NKTCL patients with low AGR require therapy that is more effective. Anti-inflammatory therapy (e.g., non-steroidal antiinflammatory agents) has been under investigation for lymphoid malignancies and may be a potential therapeutic choice for NKTCL (Braun et al., 2012; Kumar et al., 2012a; Kumar et al., 2012b). This option requires further exploration.

Several limitations exist in our study due to its retrospective, single-center design. The AGR was only assessed before first-line treatment, and changes in AGR during treatment and followup were not routinely evaluated. Therefore, we were unable to analyze the dynamic alterations to AGR and its correlation with treatment response and prognosis. Specific inflammatory and nutritional markers (such as cytokine levels and prealbumin) were not measured, and these assessments might have strengthened the study. In addition, other concurrent disorders that may have impact on the level of globulin, including monoclonal gammopathy of undetermined significance (MGUS), were not routinely assessed, which may have interfered with the interpretation of the results in this study.

\section{Conclusions}

Low pretreatment AGR is an independent predictor of poor prognosis in patients with NKTCL and provides better risk stratification in combination with the currently used prognostic indexes. As AGR may be measured at low cost through routine pretreatment laboratory tests, it could serve as a simple and effective predictor of prognosis in patients with NKTCL. In addition, the results of this single-center study must be independently validated in other cohorts.

\section{Acknowledgements}

We thank all of the physicians at Sun Yat-sen University Cancer Center for allowing us to include their patients.

\section{References}

Andersson C, Lonnroth C, Moldawer LL, Ternell M, and Lundholm K. 1990. Increased degradation of albumin in cancer is not due to conformational or chemical modifications in the albumin molecule. Journal of Surgical Research 49:23-29. DOI: http://dx.doi.org/10.1016/0022-4804(90)90105-B. 
Au WY, Weisenburger DD, Intragumtornchai T, Nakamura S, Kim WS, Sng I, Vose J, Armitage JO, and Liang R. 2009. Clinical differences between nasal and extranasal natural killer/Tcell lymphoma: a study of 136 cases from the International Peripheral T-Cell Lymphoma Project. Blood 113:3931-3937. DOI: 10.1182/blood-2008-10-185256.

Azab BN, Bhatt VR, Vonfrolio S, Bachir R, Rubinshteyn V, Alkaied H, Habeshy A, Patel J, Picon AI, and Bloom SW. 2013a. Value of the pretreatment albumin to globulin ratio in predicting long-term mortality in breast cancer patients. American Journal of Surgery 206:764-770. DOI: 10.1016/j.amjsurg.2013.03.007.

Azab B, Kedia S, Shah N, Vonfrolio S, Lu W, Naboush A, Mohammed F, and Bloom SW. $2013 \mathrm{~b}$. The value of the pretreatment albumin/globulin ratio in predicting the long-term survival in colorectal cancer. International Journal of Colorectal Disease 28:1629-1636. DOI: $10.1007 / \mathrm{s} 00384-013-1748-\mathrm{z}$.

Balkwill F and Mantovani A. 2001. Inflammation and cancer: back to Virchow? Lancet 357:539545. DOI: http://dx.doi.org/10.1016/S0140-6736(00)04046-0.

Bi XW, Li YX, Fang H, Jin J, Wang WH, Wang SL, Liu YP, Song YW, Ren H, and Dai JR. 2013. High-dose and extended-field intensity modulated radiation therapy for early-stage NK/T-cell lymphoma of Waldeyer's ring: dosimetric analysis and clinical outcome. International Journal of Radiation Oncology Biology Physics 87:1086-1093. DOI: 10.1016/j.ijrobp.2013.08.040.

Bi XW, Jiang WQ, Zhang WW, Huang JJ, Xia Y, Wang Y, Sun P, and Li ZM. 2015a. Treatment outcome of patients with advanced stage natural killer/T-cell lymphoma: elucidating the effects of asparaginase and postchemotherapeutic radiotherapy. Annals of Hematology 94:1175-1184. DOI: 10.1007/s00277-015-2336-9.

Bi XW, Zhang WW, Li ZM, Huang JJ, Xia Y, Sun P, Wang Y, and Jiang WQ. 2015b. The extent of local tumor invasion predicts prognosis in stage I nasal natural killer/T-cell lymphoma: a novel T staging system for risk stratification. Annals of Hematology 94:1515-1524. DOI:10.1007/s00277-015-2390-3.

Boonpipattanapong T, and Chewatanakornkul S. 2006. Preoperative carcinoembryonic antigen and albumin in predicting survival in patients with colon and rectal carcinomas. Journal of Clinical Gastroenterology 40:592-595.

Braun FK, Al-Yacoub N, Plotz M, Mobs M, Sterry W, and Eberle J. 2012. Nonsteroidal antiinflammatory drugs induce apoptosis in cutaneous T-cell lymphoma cells and enhance their sensitivity for TNF-related apoptosis-inducing ligand. Journal of Investigative Dermatology 132:429-439. DOI: 10.1038/jid.2011.316.

Chan JK, Jaffe ES, and Ralfkiaer E. 2001. Extranodal NK/T-cell lymphoma, nasal type. In: Jaffe ES, Harris NL, Stein H, and Vardiman JW, eds. WHO classification of tumours of 
412

413

414

415

416

417

418

419

420

421

422

423

424

425

426

427

428

429

430

431

432

433

434

435

436

437

438

439

440

441

442

443

444

445

446

447

haematopoietic and lymphoid tissues. Lyon: IARC, 204-207.

Chan JK, Quintanilla-Martinez L, Ferry JA, and Peh S-C. 2008. Extranodal NK/T-cell lymphoma, nasal type. In: Swerdlow SH, Campo E, and Harris NL, et al., eds. WHO classification of tumours of haematopoietic and lymphoid tissues. Lyon: IARC, 285-288.

Cheung MM, Chan JK, Lau WH, Ngan RK, and Foo WW. 2002. Early stage nasal NK/T-cell lymphoma: clinical outcome, prognostic factors, and the effect of treatment modality. International Journal of Radiation Oncology Biology Physics 54:182-190. DOI: http://dx.doi.org/10.1016/S0360-3016(02)02916-4.

Chim CS, Ma SY, Au WY, Choy C, Lie AK, Liang R, Yau CC, and Kwong YL. 2004. Primary nasal natural killer cell lymphoma: long-term treatment outcome and relationship with the International Prognostic Index. Blood 103:216-221. DOI: http://dx.doi.org/10.1182/blood2003-05-1401.

Colotta F, Allavena P, Sica A, Garlanda C, and Mantovani A. 2009. Cancer-related inflammation, the seventh hallmark of cancer: links to genetic instability. Carcinogenesis 30:1073-1081. DOI: $10.1093 /$ carcin/bgp127.

Coussens LM, and Werb Z. 2002. Inflammation and cancer. Nature 420:860-867. DOI: 10.1038/nature01322.

Du XJ, Tang LL, Mao YP, Sun Y, Zeng MS, Kang TB, Jia WH, Lin AH, and Ma J. 2014. The pretreatment albumin to globulin ratio has predictive value for long-term mortality in nasopharyngeal carcinoma. PLoS One 9:e94473. DOI:10.1371/journal.pone.0094473.

Duran AO, Inanc M, Karaca H, Dogan I, Berk V, Bozkurt O, Ozaslan E, Ucar M, Eroglu C, and Ozkan M. 2014. Albumin-globulin ratio for prediction of long-term mortality in lung adenocarcinoma patients. Asian Pacific Journal of Cancer Prevention 15:6449-6453. DOI:http://dx.doi.org/10.7314/APJCP.2014.15.15.6449.

Fearon KC, Falconer JS, Slater C, McMillan DC, Ross JA, and Preston T. 1998. Albumin synthesis rates are not decreased in hypoalbuminemic cachectic cancer patients with an ongoing acute-phase protein response. Annals of Surgery 227:249-254.

Gabay C, and Kushner I. 1999. Acute-phase proteins and other systemic responses to inflammation. New England Journal of Medicine 340:448-454. DOI: 10.1056/NEJM199902113400607.

Gupta D, and Lis CG. 2010. Pretreatment serum albumin as a predictor of cancer survival: a systematic review of the epidemiological literature. Nutrition Journal 9:69. DOI: 10.1186/1475-2891-9-69.

Guthrie GJ, Roxburgh CS, Farhan-Alanie OM, Horgan PG, and McMillan DC. 2013. Comparison of the prognostic value of longitudinal measurements of systemic inflammation in patients undergoing curative resection of colorectal cancer. British Journal of Cancer 
109:24-28. DOI: 10.1038/bjc.2013.330.

Hanakawa H, Orita Y, Sato Y, Takao S, Marunaka H, Morishita T, Yamashita Y, Hori Y, Domae S, Inokuchi I, Akagi S, Kondo E, Iwaki N, Motomiya K, Okumura H, Yoshino T, and Nishizaki K. 2014. Novel and simple prognostic index for nasal natural killer/T-cell lymphoma. Head Neck 36:551-556. DOI: 10.1002/hed.23322.

Huang MJ, Jiang Y, Liu WP, Li ZP, Li M, Zhou L, Xu Y, Yu CH, Li Q, Peng F, Liu JY, Luo F, and Lu Y. 2008. Early or up-front radiotherapy improved survival of localized extranodal NK/T-cell lymphoma, nasal-type in the upper aerodigestive tract. International Journal of Radiation Oncology Biology Physics 70:166-174. DOI: http://dx.doi.org/10.1016/j.ijrobp.2007.05.073.

Huang JJ, Jiang WQ, Lin TY, Huang Y, Xu RH, Huang HQ and Li ZM. 2011. Absolute lymphocyte count is a novel prognostic indicator in extranodal natural killer/T-cell lymphoma, nasal type. Ann Oncol 22: 149-155. DOI: 10.1093/annonc/mdq314.

Igarashi T, Tobe T, Kuramochi H, Akakura K, Ichikawa T, Hamano S, Suzuki N, Furuya Y, and Ito H. 2001. Serum immunosuppressive acidic protein as a potent prognostic factor for patients with metastatic renal cell carcinoma. Japanese Journal of Clinical Oncology 31:1317. DOI: $10.1093 / \mathrm{jjco} / \mathrm{hye} 004$.

Jaccard A, Gachard N, Marin B, Rogez S, Audrain M, Suarez F, Tilly H, Morschhauser F, Thieblemont C, Ysebaert L, Devidas A, Petit B, de Leval L, Gaulard P, Feuillard J, Bordessoule D, and Hermine O. 2011. Efficacy of L-asparaginase with methotrexate and dexamethasone (AspaMetDex regimen) in patients with refractory or relapsing extranodal NK/T-cell lymphoma, a phase 2 study. Blood 117:1834-1839. DOI: 10.1182/blood-201009-307454.

Kim BS, Kim DW, Im SA, Kim CW, Kim TY, Yoon SS, Heo DS, Bang YJ, Park S, Kim BK, and Kim NK. 2009. Effective second-line chemotherapy for extranodal NK/T-cell lymphoma consisting of etoposide, ifosfamide, methotrexate, and prednisolone. Annals of Oncology 20:121-128. DOI: 10.1093/annonc/mdn551.

Kim TM, Lee SY, Jeon YK, Ryoo BY, Cho GJ, Hong YS, Kim HJ, Kim SY, Kim CS, Kim S, Kim JS, Sohn SK, Song HH, Lee JL, Kang YK, Yim CY, Lee WS, Yuh YJ, Kim CW, and Heo DS. 2008. Clinical heterogeneity of extranodal NK/T-cell lymphoma, nasal type: a national survey of the Korean Cancer Study Group. Annals of Oncology 19:1477-1484. DOI: 10.1093/annonc/mdn147.

Kumar A, Vishvakarma NK, Bharti AC, and Singh SM. 2012a. Gender-specific antitumor action of aspirin in a murine model of a T-cell lymphoma bearing host. Blood Cells Molecules and Diseases 48:137-144. DOI: 10.1016/j.bcmd.2011.

Kumar A, Vishvakarma NK, Tyagi A, Bharti AC, and Singh SM. 2012b. Anti-neoplastic action 
484

485

486

487

488

489

490

491

492

493

494

495

496

497

498

499

500

501

502

503

504

505

506

507

508

509

510

511

512

513

514

515

516

517

518

519

of aspirin against a T-cell lymphoma involves an alteration in the tumour microenvironment and regulation of tumour cell survival. Bioscience Reports 32:91-104. DOI: 10.1042/BSR20110027.

Kwong YL, Kim WS, Lim ST, Kim SJ, Tang T, Tse E, Leung AY, and Chim CS. 2012. SMILE for natural killer/T-cell lymphoma: analysis of safety and efficacy from the Asia Lymphoma Study Group. Blood 120:2973-2980. DOI: 10.1182/blood-2012-05-431460.

Lee J, Suh C, Park YH, Ko YH, Bang SM, Lee JH, Lee DH, Huh J, Oh SY, Kwon HC, Kim HJ, Lee SI, Kim JH, Park J, Oh SJ, Kim K, Jung C, Park K, and Kim WS. 2006. Extranodal natural killer T-cell lymphoma, nasal-type: a prognostic model from a retrospective multicenter study. Journal of Clinical Oncology 24:612-618. DOI:

10.1200/JCO.2005.04.1384.

Li YJ, Li ZM, Xia Y, Huang JJ, Huang HQ, Xia ZJ, Lin TY, Li S, Cai XY, Wu-Xiao ZJ, and Jiang WQ. 2013b. Serum C-reactive protein (CRP) as a simple and independent prognostic factor in extranodal natural killer/T-cell lymphoma, nasal type. PLoS One 8:e64158. DOI:10.1371/journal.pone.0064158.

Li YX, Wang H, Jin J, Wang WH, Liu QF, Song YW, Wang ZY, Qi SN, Wang SL, Liu YP, Liu $\mathrm{XF}$, and Yu ZH. 2012. Radiotherapy alone with curative intent in patients with stage I extranodal nasal-type NK/T-cell lymphoma. International Journal of Radiation Oncology Biology Physics 82:1809-1815. DOI: 10.1016/j.jirobp.2010.10.040.

Li YX, Yao B, Jin J, Wang WH, Liu YP, Song YW, Wang SL, Liu XF, Zhou LQ, He XH, Lu N, and $\mathrm{Yu} \mathrm{ZH} .2006$. Radiotherapy as primary treatment for stage IE and IIE nasal natural killer/T-cell lymphoma. Journal of Clinical Oncology 24:181-189. DOI: 10.1200/JCO.2005.03.2573.

McMillan DC, Watson WS, O'Gorman P, Preston T, Scott HR, and McArdle CS. 2001. Albumin concentrations are primarily determined by the body cell mass and the systemic inflammatory response in cancer patients with weight loss. Nutrition and Cancer 39:210213. DOI: $10.1207 / \mathrm{S} 15327914 n c 39288$.

Shibutani M, Maeda K, Nagahara H, Ohtani H, Iseki Y, Ikeya T, Sugano K, and Hirakawa K. 2015. The pretreatment albumin to globulin ratio predicts chemotherapeutic outcomes in patients with unresectable metastatic colorectal cancer. BMC Cancer 15:347. DOI: 10.1186/s12885-015-1375-x.

Shipp MA, Anderson JR, Armitage JO, Bonadonna G, Brittinger G, Cabanillas F, Canellos GP, Coiffier B, Connors JM, Cowan RA, Crowther D, Dahlberg S, Engelhard M, Fisher RI, Gisselbrecht C, Horning SJ, Lepage E, Lister TA, Meerwaldt JH, Montserrat E, Nissen NI, Oken MM, Peterson BA, Tondini C, Velasquez WS, and Yead BY. 1993. A predictive model for aggressive non-Hodgkin's lymphoma: The International Non-Hodgkin's 
520

521

522

523

524

525

526

527

528

529

530

531

532

533

534

535

536

537

538

539

540

541

542

543

544

545

546

547

548

549

550

Lymphoma Prognostic Factors Project. New England Journal of Medicine 329:987-994.

DOI: 10.1056/NEJM199309303291402.

Siddiqui A, Heinzerling J, Livingston EH, and Huerta S. 2007. Predictors of early mortality in veteran patients with pancreatic cancer. American Journal of Surgery 194:362-366. DOI: http://dx.doi.org/10.1016/j.amjsurg.2007.02.007.

Suh B, Park S, Shin DW, Yun JM, Keam B, Yang HK, Ahn E, Lee H, Park JH, and Cho B. 2014. Low albumin-to-globulin ratio associated with cancer incidence and mortality in generally healthy adults. Annals of Oncology 25:2260-2266. DOI: 10.1093/annonc/mdu274.

Vose J, Armitage J, and Weisenburger D. 2008. International peripheral T-cell and natural killer/T-cell lymphoma study: pathology findings and clinical outcomes. Journal of Clinical Oncology 26:4124-4130. DOI: 10.1200/JCO.2008.16.4558.

Wang B, Li XQ, Ma X, Hong X, Lu H, and Guo Y. 2008. Immunohistochemical expression and clinical significance of P-glycoprotein in previously untreated extranodal NK/T-cell lymphoma, nasal type. American Journal of Hematology 83:795-799. DOI: 10.1002/ajh.21256.

Wang L, Wang WD, Xia ZJ, Zhang YJ, Xiang J, and Lu Y. 2014. Combination of gemcitabine, L-asparaginase, and oxaliplatin (GELOX) is superior to EPOCH or CHOP in the treatment of patients with stage IE/IIE extranodal natural killer/T cell lymphoma: a retrospective study in a cohort of 227 patients with long-term follow-up. Medical Oncology 31:860. DOI: 10.1007/s12032-014-0860-4.

Wang ZY, Liu QF, Wang H, Jin J, Wang WH, Wang SL, Song YW, Liu YP, Fang H, Ren H, Wu RY, Chen B, Zhang XM, Lu NN, Zhou LQ, and Li YX. 2012b. Clinical implications of plasma Epstein-Barr virus DNA in early-stage extranodal nasal-type NK/T-cell lymphoma patients receiving primary radiotherapy. Blood 120:2003-2010. DOI: 10.1182/blood-201206-435024.

Yamaguchi M, Kwong YL, Kim WS, Maeda Y, Hashimoto C, Suh C, Izutsu K, Ishida F, Isobe Y, Sueoka E, Suzumiya J, Kodama T, Kimura H, Hyo R, Nakamura S, Oshimi K, and Suzuki R. 2011. Phase II study of SMILE chemotherapy for newly diagnosed stage IV, relapsed, or refractory extranodal natural killer (NK)/T-cell lymphoma, nasal type: the NKCell Tumor Study Group study. Journal of Clinical Oncology 29:4410-4416. DOI: 10.1200/JCO.2011.35.6287. 
1

Overall survival (OS) and progression-free survival (PFS) for the entire cohort.

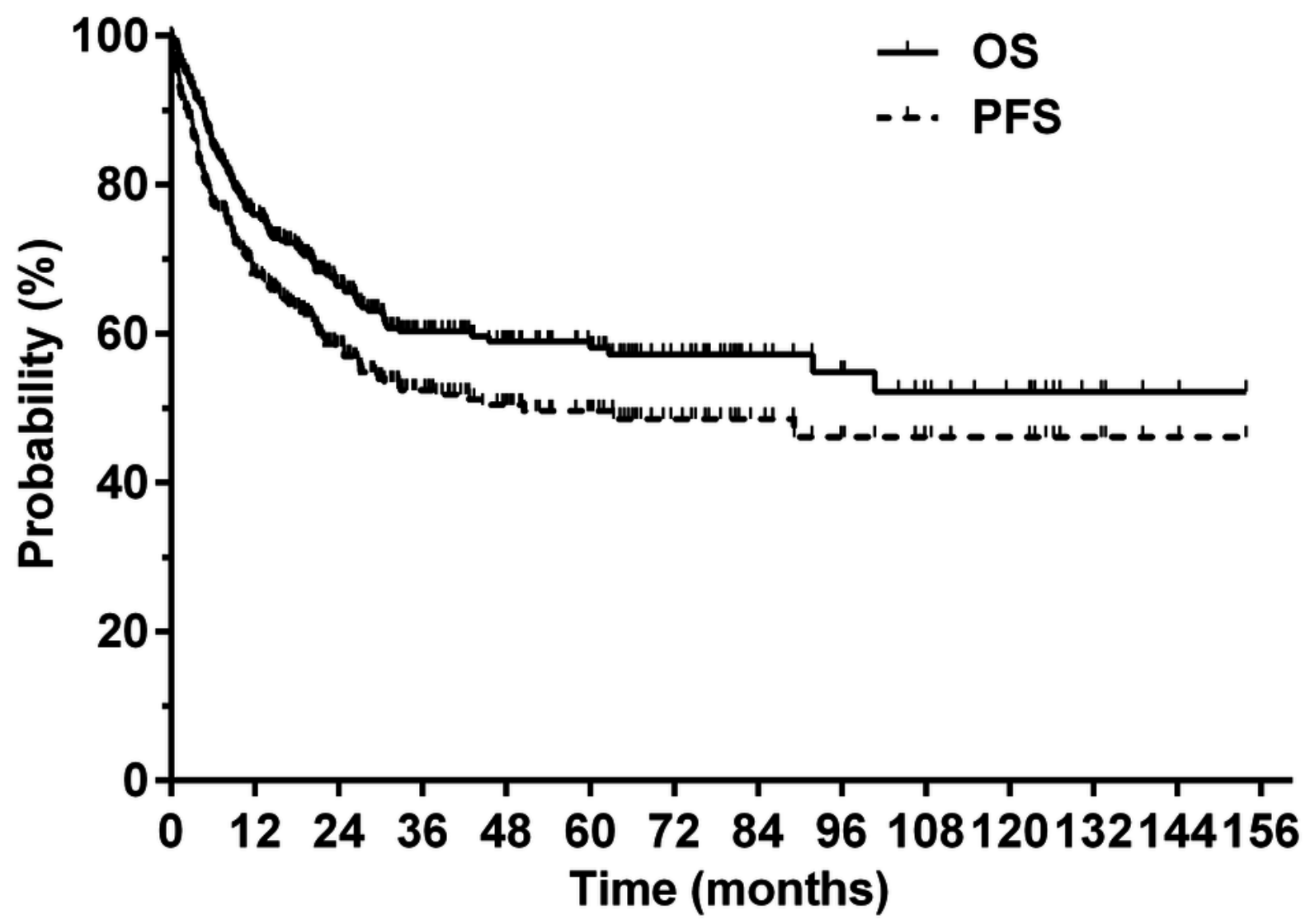


2

Prognosis of patients with NK/T-cell lymphoma according to the pretreatment serum albumin to globulin ratio (AGR).

(A) Overall survival (OS) and (B) progression-free survival (PFS) for patients with NK/T-cell lymphoma with a pretreatment serum AGR $\geq 1.3$ (solid line) or $<1.3$ (dashed line) 

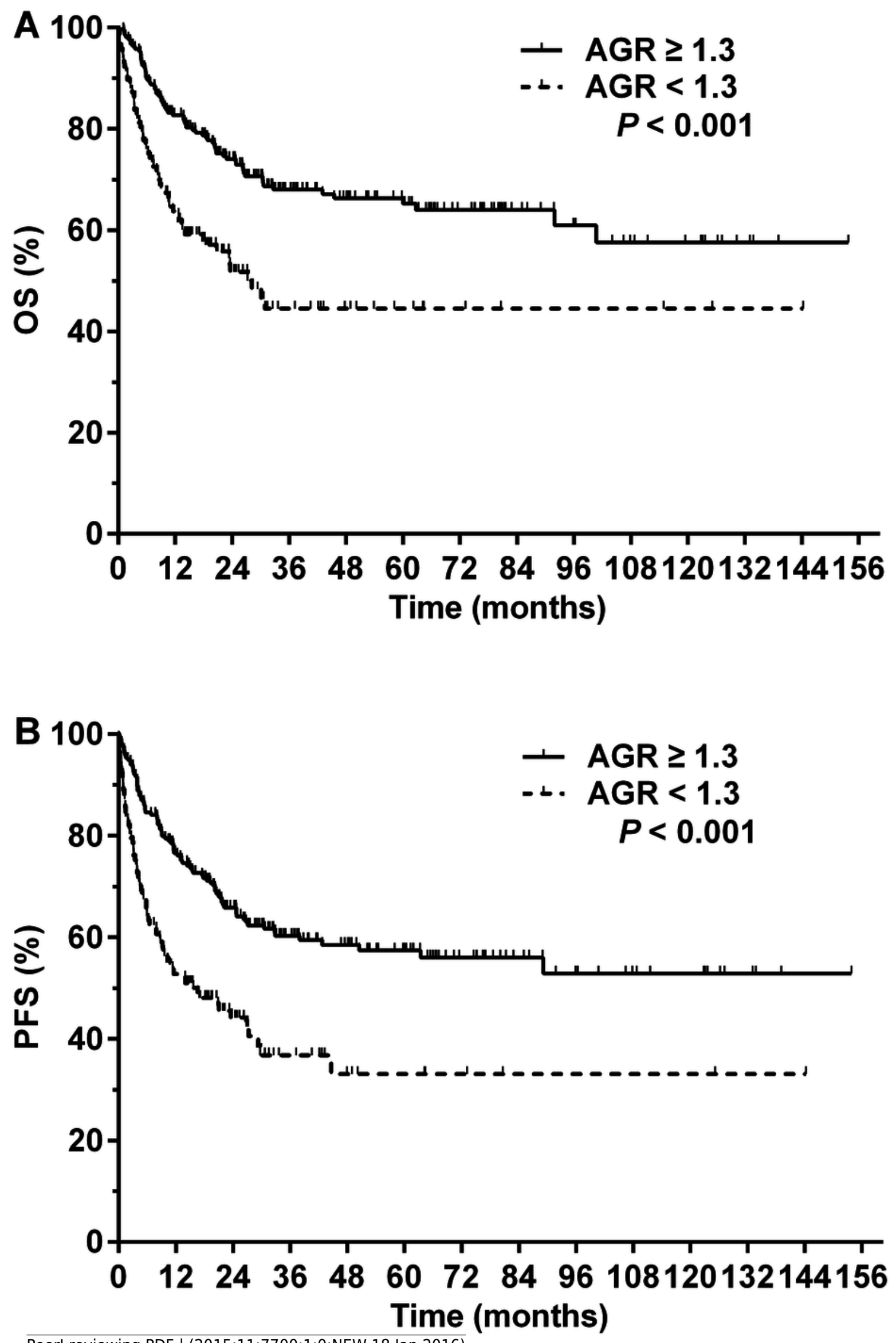
3

Overall survival (OS) for patients with NK/T-cell lymphoma with different pretreatment serum albumin to globulin ratios (AGRs) according to treatment modalities.

OS for patients with a pretreatment $A G R \geq 1.3$ (solid line) or $<1.3$ (dashed line) who received (A) chemotherapy alone, (B) radiotherapy with or without chemotherapy, (C) anthracycline-based chemotherapy, or (D) asparaginase-containing chemotherapy.
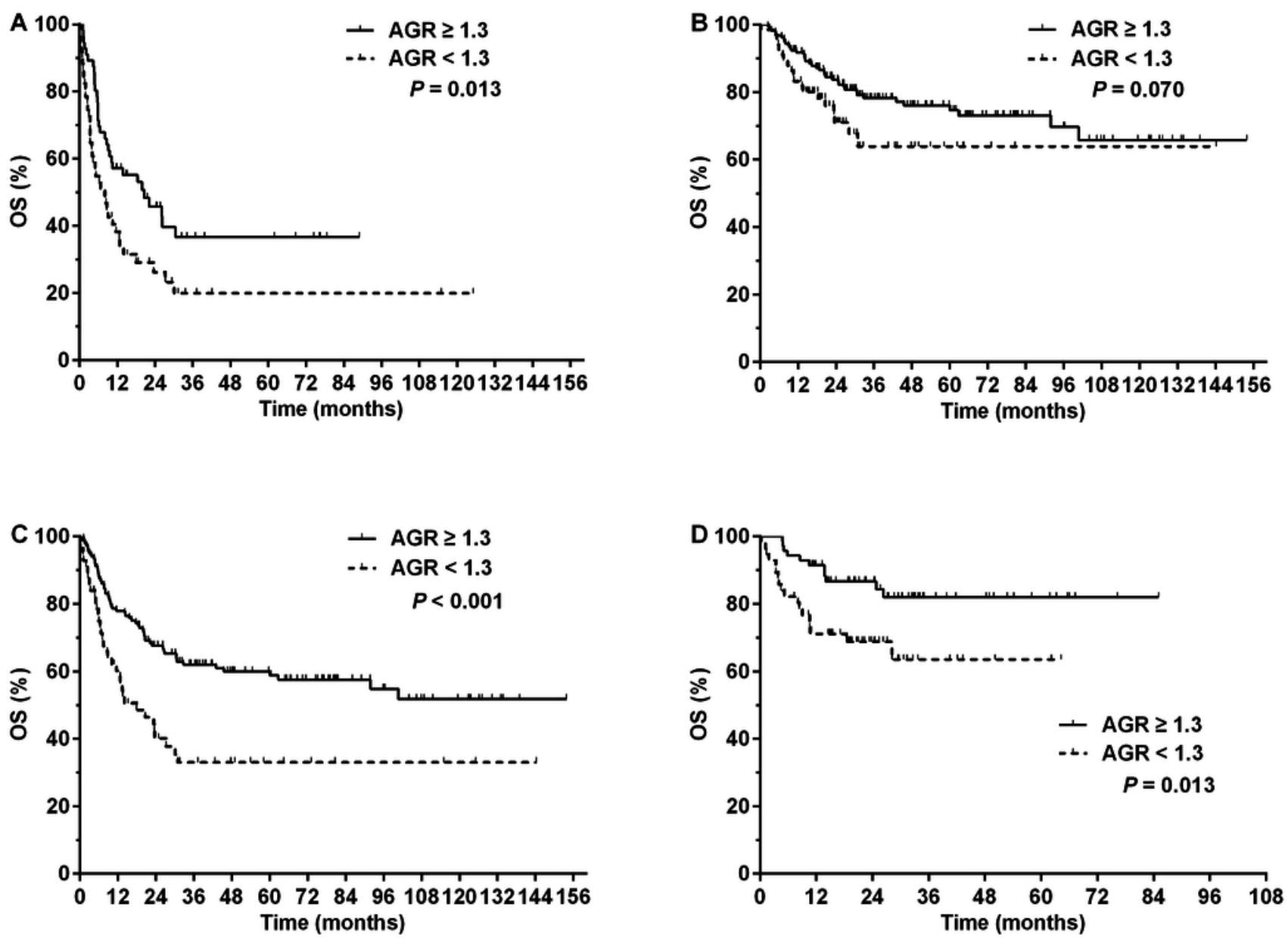
4

Overall survival (OS) for patients with NK/T-cell lymphoma according to prognostic indexes.

OS for patients stratified by (A) the International Prognostic Index (IPI), (B) IPI combined with albumin to globulin ratio (AGR), (C) natural killer/T-cell lymphoma prognostic index (NKPI), and (D) NKPI combined with AGR. Abbreviations: LR: low risk; IR: intermediate risk; HR: high risk.
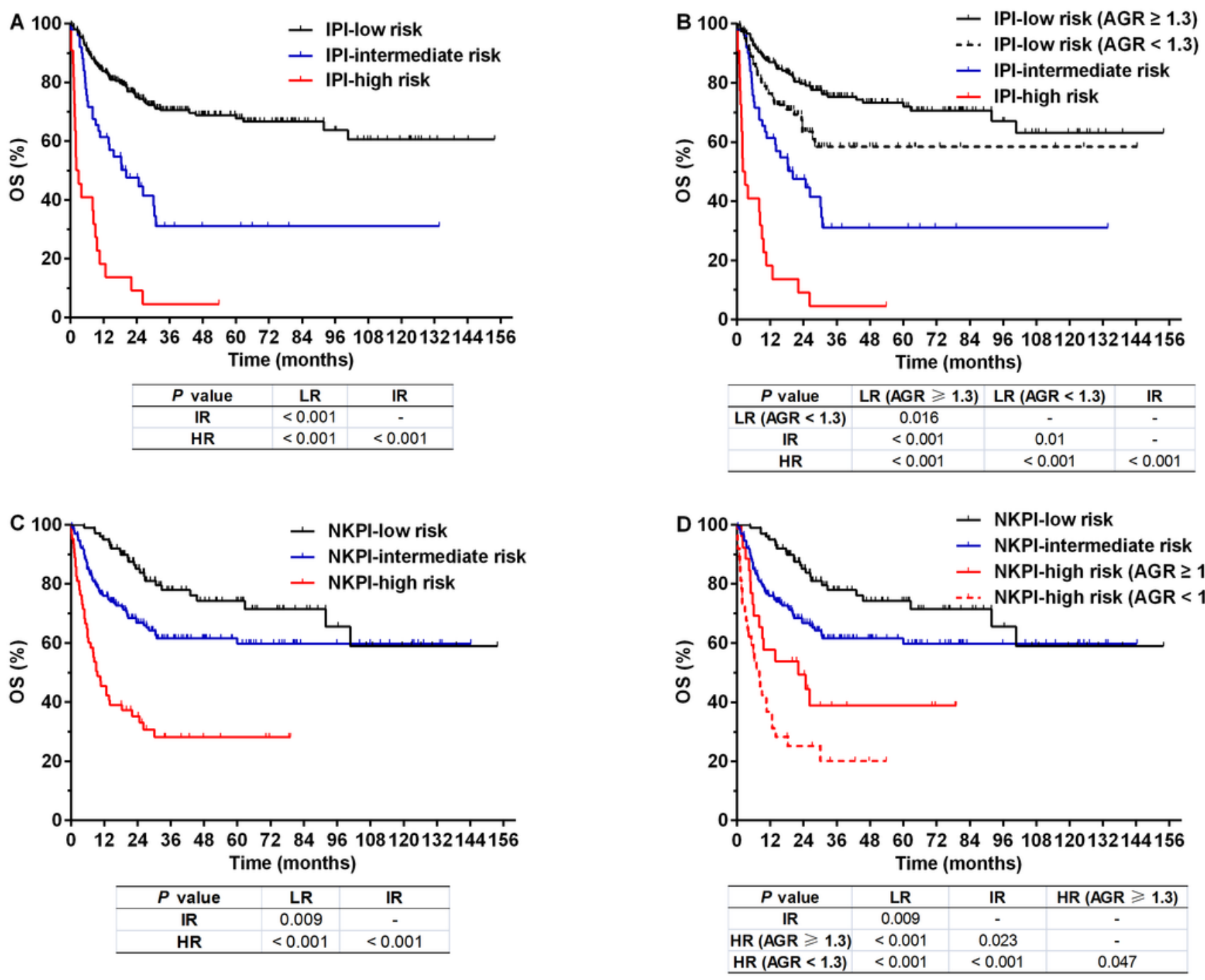


\section{Table $\mathbf{1}$ (on next page)}

Differentiating power of cut-off values for pretreatment albumin to globulin ratio on overall survival of patients with NK/T-cell lymphoma. 
1 Table 1. Differentiating power of cut-off values for pretreatment albumin to globulin ratio on overall survival of 2 patients with NK/T-cell lymphoma.

\begin{tabular}{cccc}
\hline Cut-off & \multirow{2}{*}{$\begin{array}{c}\text { No. of patients } \\
\text { value }\end{array}$} & \multicolumn{2}{c}{ Overall survival } \\
\cline { 3 - 4 } (low/high) & Chi-squared & $P$ value \\
\hline 1.0 & $24 / 307$ & 5.174 & 0.023 \\
1.1 & $52 / 279$ & 6.620 & 0.010 \\
1.2 & $80 / 251$ & 9.589 & 0.002 \\
1.3 & $117 / 214$ & 17.418 & 0.000 \\
1.4 & $172 / 159$ & 6.662 & 0.010 \\
1.5 & $220 / 111$ & 3.206 & 0.073 \\
1.6 & $258 / 73$ & 2.563 & 0.109 \\
1.7 & $289 / 42$ & 2.618 & 0.106 \\
1.8 & $304 / 27$ & 1.953 & 0.162 \\
1.9 & $314 / 17$ & 3.914 & 0.048 \\
2.0 & $321 / 10$ & 3.583 & 0.058 \\
\hline
\end{tabular}

3 


\section{Table 2 (on next page)}

The clinical characteristics and treatment modalities of patients with NK/T-cell lymphoma.

"Continuous variables are presented as medians (range), and categorical variables are shown as frequencies and percentages. Abbreviations: AGR: albumin to globulin ration; BMI: body mass index; CRP: C-reactive protein; ECOG: Eastern Cooperative Oncology Group; ESR: erythrocyte sedimentation rate; EUAT: extra-upper aerodigestive tract; IPI: International Prognostic Index; LDH: lactate dehydrogenase; NKPI: natural killer/T-cell lymphoma prognostic index; RT: radiotherapy; UAT: upper aerodigestive tract; WBC: white blood cell. 
1 Table 2. The clinical characteristics and treatment modalities of patients with NK/T-cell lymphoma.

\begin{tabular}{|c|c|c|c|c|}
\hline Parameters* & $\begin{array}{l}\text { Total } \\
n(\%)\end{array}$ & $\begin{array}{c}\mathrm{AGR}<1.3 \\
n(\%)\end{array}$ & $\begin{array}{c}\mathrm{AGR} \geq 1.3 \\
n(\%)\end{array}$ & $\begin{array}{c}P \\
\text { value }\end{array}$ \\
\hline Overall & $331(100)$ & $117(100)$ & $214(100)$ & \\
\hline Male gender & $227(68.6)$ & $75(64.1)$ & $152(71.0)$ & 0.194 \\
\hline Age (years) & $42(11-80)$ & $44(11-77)$ & $41(13-80)$ & 0.069 \\
\hline Age $>60$ years & $51(15.4)$ & $24(20.5)$ & $27(12.6)$ & 0.057 \\
\hline BMI $\left(\mathrm{kg} / \mathrm{m}^{2}\right)$ & $21.2(13.7-44.0)$ & $20.4(13.7-44.0)$ & $21.4(14.8-44.0)$ & 0.010 \\
\hline $\mathrm{BMI}<18.5 \mathrm{~kg} / \mathrm{m}^{2}$ & $53(16.0)$ & $26(22.2)$ & $27(12.6)$ & 0.023 \\
\hline ECOG score $\geq 2$ & $52(15.7)$ & $33(28.2)$ & $19(8.9)$ & 0.000 \\
\hline \multicolumn{5}{|l|}{ Primary site } \\
\hline UAT & $294(88.8)$ & $98(83.8)$ & $196(91.6)$ & 0.031 \\
\hline EUAT & $37(11.2)$ & $19(16.2)$ & $18(8.4)$ & \\
\hline \multicolumn{5}{|l|}{ Ann Arbor stage } \\
\hline I-II & $269(81.3)$ & $87(74.4)$ & $182(85.0)$ & 0.017 \\
\hline III-IV & $62(18.7)$ & $30(25.6)$ & $32(15.0)$ & \\
\hline B symptoms & $173(52.3)$ & $86(73.5)$ & $87(40.7)$ & 0.000 \\
\hline Elevated LDH & $96(29.0)$ & $47(40.2)$ & 49 (22.9) & 0.001 \\
\hline Involvement of regional lymph nodes & $119(36.0)$ & $58(49.6)$ & $61(28.5)$ & 0.000 \\
\hline Extranodal sites $\geq 2$ & $44(13.3)$ & $21(17.9)$ & $23(10.7)$ & 0.065 \\
\hline \multicolumn{5}{|l|}{ IPI score } \\
\hline Low risk (0-1) & $259(78.2)$ & $61(69.2)$ & $178(83.2)$ & 0.000 \\
\hline Intermediate risk (2-3) & $50(15.1)$ & $20(17.1)$ & $30(14.0)$ & \\
\hline High risk (4-5) & $22(6.6)$ & $16(13.7)$ & $6(2.8)$ & \\
\hline \multicolumn{5}{|l|}{ NKPI score } \\
\hline Low risk(0) & $101(30.5)$ & $12(10.3)$ & $89(41.6)$ & 0.000 \\
\hline Intermediate risk(1-2) & $167(50.5)$ & $68(58.1)$ & $99(46.3)$ & \\
\hline High risk (3-4) & $63(19.0)$ & $37(31.6)$ & $26(12.1)$ & \\
\hline Total protein $(\mathrm{g} / \mathrm{L})$ & $72.1(32.5-89.2)$ & $72.2(32.5-89.2)$ & $72.0(41.5-85.7)$ & 0.450 \\
\hline Serum albumin $(g / L)$ & $41.5(21.6-54.4)$ & $38.0(21.6-45.6)$ & $43.5(26.8-54.4)$ & 0.000 \\
\hline Hypoalbuminemia $(<35 \mathrm{~g} / \mathrm{L})$ & $38(11.5)$ & $29(24.8)$ & $9(4.2)$ & 0.000 \\
\hline WBC count $(\mathrm{k} / \mathrm{cc})$ & $5.9(0.9-23.0)$ & $5.7(1.6-15.6)$ & $6.0(0.9-23.0)$ & 0.262 \\
\hline Neutrophil count (k/cc) & $3.5(0.4-20.1)$ & $3.3(0.6-12.9)$ & $3.5(0.4-20.1)$ & 0.644 \\
\hline Lymphocyte count (k/cc) & $1.5(0.2-5.4)$ & $1.4(0.2-4.5)$ & $1.6(0.3-5.4)$ & 0.032 \\
\hline $\mathrm{CRP}(n=246, \mathrm{mg} / \mathrm{L})$ & $6.6(0.2-154.9)$ & $12.8(0.5-154.9)$ & $3.9(0.2-87.6)$ & 0.000 \\
\hline $\operatorname{ESR}(\mathrm{n}=117, \mathrm{~mm} / \mathrm{h})$ & $17(1-110)$ & $41(3-104)$ & $11(1-110)$ & 0.000 \\
\hline Serum creatinine $(\mu \mathrm{mol} / \mathrm{L})$ & $\begin{array}{c}67.1(31.6- \\
116.0)\end{array}$ & $\begin{array}{c}64.1(32.8- \\
108.0)\end{array}$ & $\begin{array}{c}69.3(31.6- \\
116.0)\end{array}$ & 0.011 \\
\hline \multicolumn{5}{|l|}{ Treatment modalities } \\
\hline Chemotherapy alone & $107(32.3)$ & $51(43.6)$ & $56(26.2)$ & 0.001 \\
\hline $\mathrm{RT} \pm$ chemotherapy & $224(67.7)$ & $66(56.4)$ & $158(73.8)$ & \\
\hline
\end{tabular}


Chemotherapeutic regimen

Asparaginase-containing

$\begin{array}{cccc}125(39.3) & 55(49.1) & 70(34.0) & 0.008 \\ 193(60.7) & 57(50.9) & 136(66.0) & \\ 4.6(18.0-74.0) & 54.6(20.0-74.0) & 54.6(18.0-64.0) & 0.166 \\ 4(0-10) & 4(1-9) & 4(0-10) & 0.933\end{array}$

Anthracycline-based

Radiation dose (Gy)

$4(0-10)$

$4(1-9)$

0.933

$2{ }^{*}$ Continuous variables are presented as medians (range), and categorical variables are shown as frequencies and 3 percentages.

4 Abbreviations: AGR: albumin to globulin ration; BMI: body mass index; CRP: C-reactive protein; ECOG: Eastern 5 Cooperative Oncology Group; ESR: erythrocyte sedimentation rate; EUAT: extra-upper aerodigestive tract; IPI:

6 International Prognostic Index; LDH: lactate dehydrogenase; NKPI: natural killer/T-cell lymphoma prognostic index;

7 RT: radiotherapy; UAT: upper aerodigestive tract; WBC: white blood cell. 


\section{Table 3 (on next page)}

Univariate analysis of prognostic factors in patients with NK/T-cell lymphoma.

"The hazard ratio gives the increase in risk for each unit increase for the continuous variables and gives the increased risk relative to the reference category for the categorical variables. Abbreviations: AGR: albumin to globulin ration; ASP: asparaginase; BMI: body mass index; $\mathrm{Cl}$ : confidence interval; CRP: C-reactive protein; ECOG: Eastern Cooperative Oncology Group; ESR: erythrocyte sedimentation rate; EUAT: extra-upper aerodigestive tract; HR: hazard ratio; IPI: International Prognostic Index; LDH: lactate dehydrogenase; NKPI: natural killer/T-cell lymphoma prognostic index; OS: overall survival; PFS: progression free survival; RT: radiotherapy; UAT: upper aerodigestive tract; WBC: white blood cell. 
1 Table 3. Univariate analysis of prognostic factors in patients with NK/T-cell lymphoma.

\begin{tabular}{|c|c|c|c|c|}
\hline \multirow[b]{2}{*}{ Variable } & \multicolumn{2}{|l|}{ OS } & \multicolumn{2}{|l|}{ PFS } \\
\hline & $\operatorname{HR}(95 \% \mathrm{CI})^{*}$ & $\begin{array}{c}P \\
\text { value }\end{array}$ & $\operatorname{HR}(95 \% \mathrm{CI})^{*}$ & $\begin{array}{c}P \\
\text { value }\end{array}$ \\
\hline Gender (female vs. male) & $0.70(0.47-1.05)$ & 0.081 & $0.80(0.56-1.14)$ & 0.215 \\
\hline Age ( $>60$ vs. $\leq 60$ years $)$ & $2.27(1.51-3.40)$ & 0.000 & $1.61(1.07-2.41)$ & 0.022 \\
\hline BMI & $0.97(0.92-1.02)$ & 0.234 & $0.99(0.95-1.04)$ & 0.744 \\
\hline ECOG score $(\geq 2$ vs. $0-1)$ & $4.04(2.57-5.93)$ & 0.000 & $4.48(3.14-6.39)$ & 0.000 \\
\hline Primary site (EUAT vs. UAT) & $1.75(1.09-2.83)$ & 0.022 & $2.36(1.54-3.60)$ & 0.000 \\
\hline Stage (III-IV vs. I-II) & $3.63(2.50-5.27)$ & 0.000 & $3.88(2.75-5.48)$ & 0.000 \\
\hline B symptoms (yes vs. no) & $1.65(1.16-2.36)$ & 0.006 & $1.77(1.27-2.45)$ & 0.001 \\
\hline LDH (elevated vs. normal) & $2.58(1.81-3.67)$ & 0.000 & $2.30(1.67-3.19)$ & 0.000 \\
\hline Involvement of regional lymph nodes & $2.10(1.48-2.98)$ & 0.000 & $2.15(1.57-2.97)$ & 0.000 \\
\hline Extranodal sites ( $\geq 2$ vs. $0-1)$ & $4.38(2.94-6.53)$ & 0.000 & $5.05(3.46-7.38)$ & 0.000 \\
\hline AGR per unit increase & $0.32(0.17-0.61)$ & 0.000 & $0.38(0.22-0.68)$ & 0.001 \\
\hline $\operatorname{AGR}(<1.3$ vs. $\geq 1.3)$ & $2.09(1.47-2.97)$ & 0.000 & $2.09(1.51-2.88)$ & 0.000 \\
\hline Total protein & $0.91(0.96-0.98)$ & 0.000 & $0.97(0.96-0.99)$ & 0.000 \\
\hline Serum albumin & $0.90(0.87-0.93)$ & 0.000 & $0.90(0.87-0.93)$ & 0.000 \\
\hline WBC count & $0.92(0.85-0.99)$ & 0.026 & $0.94(0.87-1.00)$ & 0.062 \\
\hline Neutrophil count & $0.95(0.88-1.04)$ & 0.269 & $0.98(0.91-1.05)$ & 0.511 \\
\hline Lymphocyte count & $0.50(0.37-0.68)$ & 0.000 & $0.52(0.39-0.69)$ & 0.000 \\
\hline $\mathrm{CRP}(n=246)$ & $1.01(1.00-1.02)$ & 0.008 & $1.01(1.00-1.02)$ & 0.003 \\
\hline $\operatorname{ESR}(n=117)$ & $1.00(0.99-1.01)$ & 0.647 & $1.00(0.99-1.01)$ & 0.737 \\
\hline Serum creatinine & $1.00(0.99-1.01)$ & 0.552 & $1.00(0.99-1.01)$ & 0.979 \\
\hline IPI score & $1.74(1.55-1.95)$ & 0.000 & $1.70(1.53-1.89)$ & 0.000 \\
\hline NKPI score & $1.65(1.43-1.90)$ & 0.000 & $1.65(1.45-1.88)$ & 0.000 \\
\hline $\begin{array}{l}\text { Treatment (chemo alone vs. RT } \pm \\
\text { chemo) }\end{array}$ & $4.55(3.19-6.49)$ & 0.000 & $4.31(3.12-5.95)$ & 0.000 \\
\hline $\begin{array}{l}\text { Chemotherapeutic regimens } \\
\text { (anthracycline-based vs. ASP-containing) }\end{array}$ & $1.92(1.26-2.93)$ & 0.002 & $2.00(1.37-2.92)$ & 0.000 \\
\hline
\end{tabular}

$2{ }^{*}$ The hazard ratio gives the increase in risk for each unit increase for the continuous variables and gives the 3 increased risk relative to the reference category for the categorical variables.

4 Abbreviations: AGR: albumin to globulin ration; ASP: asparaginase; BMI: body mass index; CI: confidence 5 interval; CRP: C-reactive protein; ECOG: Eastern Cooperative Oncology Group; ESR: erythrocyte sedimentation 6 rate; EUAT: extra-upper aerodigestive tract; HR: hazard ratio; IPI: International Prognostic Index; LDH: lactate 7 dehydrogenase; NKPI: natural killer/T-cell lymphoma prognostic index; OS: overall survival; PFS: progression 8 free survival; RT: radiotherapy; UAT: upper aerodigestive tract; WBC: white blood cell. 


\section{Table 4 (on next page)}

Multivariate analysis of prognostic factors in patients with NK/T-cell lymphoma.

"The hazard ratio gives the increase in risk for each unit increase for the continuous variables and gives the increased risk relative to the reference category for the categorical variables. Abbreviations: AGR: albumin to globulin ration; ASP: asparaginase; $\mathrm{Cl}$ : confidence interval; ECOG: Eastern Cooperative Oncology Group; EUAT: extra-upper aerodigestive tract; HR: hazard ratio; LDH: lactate dehydrogenase; OS: overall survival; PFS: progression free survival; RT: radiotherapy; UAT: upper aerodigestive tract. 
1 Table 4.Multivariate analysis of prognostic factors in patients with NK/T-cell lymphoma.

\begin{tabular}{|c|c|c|c|c|}
\hline \multirow[b]{2}{*}{ Variable } & \multicolumn{2}{|l|}{ OS } & \multicolumn{2}{|l|}{ PFS } \\
\hline & $\operatorname{HR}(95 \% \mathrm{CI})^{*}$ & $\begin{array}{c}P \\
\text { value }\end{array}$ & $\operatorname{HR}(95 \% \mathrm{CI})^{*}$ & $\begin{array}{c}P \\
\text { value }\end{array}$ \\
\hline Age ( $>60$ vs. $\leq 60$ years $)$ & $\begin{array}{c}2.82(1.80- \\
4.41)\end{array}$ & 0.000 & $\begin{array}{c}1.87(1.23- \\
2.84)\end{array}$ & 0.004 \\
\hline ECOG score ( $\geq 2$ vs. $0-1)$ & $\begin{array}{l}2.18(1.29- \\
3.67)\end{array}$ & 0.004 & $\begin{array}{l}1.56(1.02- \\
2.40)\end{array}$ & 0.040 \\
\hline Primary site (EUAT vs. UAT) & $\begin{array}{c}2.34(1.29- \\
4.22)\end{array}$ & 0.005 & - & - \\
\hline Stage (III-IV vs. I-II) & - & - & - & - \\
\hline B symptoms (yes vs. no) & - & - & - & - \\
\hline LDH (elevated vs. normal) & $\begin{array}{l}1.54(1.01- \\
2.36)\end{array}$ & 0.047 & - & - \\
\hline Involvement of regional lymph nodes & - & - & $\begin{array}{l}1.56(1.10- \\
2.20)\end{array}$ & 0.013 \\
\hline Extranodal sites ( $\geq 2$ vs. $0-1$ ) & $\begin{array}{l}2.14(1.31- \\
3.50)\end{array}$ & 0.002 & $\begin{array}{l}2.50(1.60- \\
3.91)\end{array}$ & 0.000 \\
\hline AGR $(<1.3$ vs. $\geq 1.3)$ & $\begin{array}{c}1.74(1.18- \\
2.56)\end{array}$ & 0.005 & $\begin{array}{c}1.73(1.21- \\
2.48)\end{array}$ & 0.003 \\
\hline Lymphocyte count $(\mathrm{k} / \mathrm{cc})$ & $\begin{array}{c}0.69(0.51- \\
0.92)\end{array}$ & 0.012 & $\begin{array}{l}0.75(0.58- \\
0.97)\end{array}$ & 0.028 \\
\hline Treatment (chemo alone vs. RT \pm chemo) & $\begin{array}{l}2.88(1.90- \\
4.36)\end{array}$ & 0.000 & $\begin{array}{l}2.61(1.81- \\
3.75)\end{array}$ & 0.000 \\
\hline $\begin{array}{l}\text { Chemotherapeutic regimens } \\
\text { (anthracycline-based vs. ASP-containing) }\end{array}$ & $\begin{array}{l}2.32(1.51- \\
3.56)\end{array}$ & 0.000 & $\begin{array}{l}2.51(1.71- \\
3.69)\end{array}$ & 0.000 \\
\hline
\end{tabular}

$2{ }^{*}$ The hazard ratio gives the increase in risk for each unit increase for the continuous variables and gives the increased 3 risk relative to the reference category for the categorical variables.

4 Abbreviations: AGR: albumin to globulin ration; ASP: asparaginase; CI: confidence interval; ECOG: Eastern 5 Cooperative Oncology Group; EUAT: extra-upper aerodigestive tract; HR: hazard ratio; LDH: lactate dehydrogenase; 6 OS: overall survival; PFS: progression free survival; RT: radiotherapy; UAT: upper aerodigestive tract. 